\title{
Effect of Banana Leaf Bath on Blood Pressure, Pulse Rate, and its Related Variables in Healthy Individuals
}

\author{
M. Fathima-Jebin', A. Mooventhan², N. Manavalan'1 \\ Departments of ${ }^{1}$ Naturopathy and ${ }^{2}$ Research Government Yoga and Naturopathy Medical College, Chennai, Tamil Nadu, India \\ ORCID: \\ M. Fathima-Jebin: 0000-0003-4118-7388 \\ A. Mooventhan: 0000-0002-2149-9694 \\ N. Manavalan: 0000-0002-8754-7249
}

\section{Abstract}

Introduction: Sunbath (heliotherapy) is a popular treatment modality being used since ancient times in many parts of the world. Banana leaf bath (BLB), a type of sunbath, is commonly employed in the treatment of various diseases in India. This study was conducted to evaluate the effect of BLB on blood pressure (BP) in healthy individuals. Materials and Methods: A single group pretest and posttest study design was adopted. Twenty ( 9 males, 11 females) healthy individuals aged 23.80 \pm 3.93 years were recruited. All the subjects underwent a 30-min session of BLB. Assessments such as systolic-BP (SBP), diastolic-BP (DBP), and pulse rate (PR) were measured using an automatic BP monitor before and after the intervention, while pulse pressure (PP), mean arterial pressure (MAP), rate pressure product (RPP), and double product (Do-P) were derived using standard formula. Statistical analysis was performed using Statistical Package for the Social Sciences version-16. Results: Results of this study showed a significant increase in SBP, PP, and MAP with a significant reduction in PR and no significant difference in DBP, RPP, and Do-P in the posttest assessment compared with baseline assessment. However, subgroups (male group and female group) analysis showed the presence of a significant increase in RPP in male participants unlike in female participants. Conclusion: Results of this study suggest that 30 min of BLB might increases SBP, PP, and MAP and reduces PR with and without affecting cardiac workload in males and females, respectively.

Keywords: Banana (plantain) leaf bath, blood pressure, heart, heliotherapy, naturopathy

\section{INTRODUCTION}

Hypertension remains a major societal problem throughout the worldwide and is being increased not only in elderly population but also in younger population. The increased prevalence of traditional risk factors in the young, including obesity, diabetes mellitus, and renal disease, increases the risk of developing hypertension in younger adults $^{[1]}$ (i.e.,18-39 years). Pathological changes to the vasculature and myocardium are often caused by cumulative early life exposure to high blood pressure (BP). High BP in young adulthood is associated with increased risks of cardiovascular disease (CVD) and mortality decades later, independent of later life BP levels. ${ }^{[2]}$

Received: 17-05-2021 Revised: 27-07-2021 Accepted: 30-07-2021

Published Online: 25-09-2021

\begin{tabular}{|l|l|}
\hline \multicolumn{3}{|c|}{ Access this article online } \\
\hline Quick Response Code: & Website: \\
& \\
http://www.ijcva.com
\end{tabular}

The sun has been a central factor in human existence. Since ancient days, medical practitioners use sunlight as a healing and restorative element in the management of several diseases. Sun therapy, also known as heliotherapy $($ Helios $=$ sun in classical Greek), was a popular modality in treating patients with skin, bone, and pulmonary tuberculosis in the early $20^{\text {th }}$ century in various parts of the world including European countries and the United States of America. Although heliotherapy was superseded by antibiotic therapy and not being used in tuberculosis, it is still practiced for a number of illnesses

Address for correspondence: Dr. A. Mooventhan, Department of Research, Government Yoga and Naturopathy Medical College, Arumbakkam, Chennai - 600 106, Tamil Nadu, India. E-mail: dr.mooventhan@gmail.com

This is an open access journal, and articles are distributed under the terms of the Creative Commons Attribution-NonCommercial-ShareAlike 4.0 License, which allows others to remix, tweak, and build upon the work non-commercially, as long as appropriate credit is given and the new creations are licensed under the identical terms.

For reprints contact: WKHLRPMedknow_reprints@wolterskluwer.com

How to cite this article: Fathima-Jebin M, Mooventhan A, Manavalan N. Effect of banana leaf bath on blood pressure, pulse rate, and its related variables in healthy individuals. Int J Cardiovasc Acad 2021;7:88-91. 
such as rickets, seasonal affective disorders, psoriasis, and a variety of other skin conditions. ${ }^{[3]}$

Conventionally, banana plant has been used to manage communicable (e.g., tuberculosis, smallpox, syphilis) and noncommunicable (e.g., diabetes, hypertension, and cancer) diseases particularly in Asia and Africa. ${ }^{[4,5]}$ Various parts of the banana plants (i.e., fruits, peel, leaves, roots, and pseudostem) are used orally or topically as remedies in folk medicine and demonstrated to have medicinal potential. ${ }^{[6]}$ Modern science has begun investigating banana leaf, which has a long history of medicinal properties and traditional value in India. ${ }^{[5]}$ For example, the tribals of Western Ghats use banana leaves for bandaging cuts, blisters, and ulcers; ${ }^{[7]}$ and dermatologists use banana leaf spread over the bedsheet for patients with toxic epidermal necrolysis, pemphigus, and burns. ${ }^{[8]}$ The German Commission E, similar to the Food And Drug Administration in United States of America, has approved the medicinal uses of plantain leaves, which was found to be helpful in easing coughs, irritation of the mucous membranes, upper respiratory tract infections, and also in cardiovascular issues. ${ }^{[5]}$

Banana leaf bath (BLB) (lie down in a place with the direct sun slight exposure, while covering the body with banana leaves ${ }^{[9]}$ is one of the age-old heliotherapy procedures employed in many naturopathy hospital and clinics as a detoxification therapy through profuse sweating to treat skin diseases (e.g., psoriasis), obesity, and other metabolic disorders. ${ }^{[10]}$ Although BLB is being used in various metabolic disorders, it is not recommended by naturopathy physician to the people with severe hypertension and uncontrolled diabetes. However, to the best of our knowledge, there is no known study reporting cardiovascular effect of BLB either in healthy individuals or in patients with hypertension/diabetes. Thus, this study was conducted to evaluate the effect of BLB on BP, pulse rate (PR), and its' related variables in healthy individuals.

\section{Materials And Methods}

\section{The study design}

A single group pretest and posttest experimental study design was adopted for this pilot study. All the subjects underwent a 30-min session of BLB. Assessments were taken before and after the intervention.

\section{Participants}

Twenty (9 males, 11 females) healthy individuals with the mean \pm standard deviation age of $23.80 \pm 3.93$ years were recruited from a residential college located in South India. Both male and female participants aged 18-39 years were included in the study. Participants with a history of photosensitivity, chronic alcoholism and smoking, systemic and/or mental illness, weak and debilitating individuals, systolic BP (SBP) ( $<90$ or $>140 \mathrm{mmHg})$, diastolic BP (DBP) $(<60 \mathrm{mmHg}$ or $>90 \mathrm{mmHg})$, PR $(<60$ beats $/ \mathrm{min}$ or $>90$ beats $/ \mathrm{min}$ ), and those not willing to participate in the study were excluded from this study.

\section{Assessments}

Assessment of SBP, DBP, and PR was measured using a noninvasive arm type automatic BP (BP) monitor (MJ701f, Rossmax International Ltd., Taiwan). Consecutive three measurements were taken before and immediately after the intervention. Average of all the three measurements was considered as a final value. Assessments such as pulse pressure (PP), mean arterial pressure (MAP), rate pressure product (RPP), and double product (Do-P) were derived by using following formulas: PP was calculated as (SBP - DBP); $\mathrm{MAP}$ as $(\mathrm{DBP}+1 / 3 \mathrm{PP}) ; \mathrm{RPP}$ as $(\mathrm{PR} \times \mathrm{SBP} / 100)$; and Do-P as $(\mathrm{PR} \times \mathrm{MAP} / 100) .{ }^{[11]}$

\section{Intervention}

All the participants underwent $30 \mathrm{~min}$ of BLB in the morning between 8:00 am and 9:30 am. The procedure of BLB: Each participant was instructed to lie down in supine position over the banana leaves kept on a mat in an open space (to get direct sunlight exposure). Then, the participant was wrapped with the banana leaves and tied with 4-6 ropes. The entire body was covered with plantain leaves with a small slit on the leaves above the nostrils to facilitate breathing. Then, the participant was left for $30 \mathrm{~min}$ in the sunlight followed by a cold affusion for a minute was given. ${ }^{[9]}$

\section{Data analysis}

The data were entered in the Microsoft Excel 2007 (Microsoft Corporation, Redmond, Washington, United States of America). All the data were checked for normality using Kolmogorov-Smirnov test. Statistical analysis was performed using paired samples $t$-test (for data that were normally distributed), and Wilcoxon signed-rank test (for data that were not normally distributed) using the Statistical Package for the Social Sciences (SPSS) for Windows, Version 16.0. Chicago, Illinois, USA SPSS Inc. $P<0.05$ was considered statistically significant.

\section{Ethical statement}

The study protocol was approved by the Institutional Ethics Committee, Government Yoga and Naturopathy Medical College, Chennai (Ref. No: RES/IEC-GYNMC/2017/029) on 30 March 2017. Informed consent was obtained in written from all the participants.

\section{RESULTS}

Of 32 participants screened for eligibility, 12 participants did not fulfill the criteria $([n=1] \mathrm{SBP}<90 ;[n=7]$ $\mathrm{DBP}<60 ;[n=1] \mathrm{PR}<60 ;[n=2] \mathrm{PR}>90 ;[n=1]$ SBP <90; DBP and PR <60) and thus not included in the study. Recruited 20 participants ( 9 males and 11 females) demographic details are as follows: age $=23.80 \pm 3.93$ years; height $=161.80 \pm 8.13 \mathrm{~cm}$; weight $=58.65 \pm 9.98 \mathrm{~kg}$; and body mass index $=22.23 \pm 2.38 \mathrm{~kg} / \mathrm{m}^{2}$. All the 20 participants underwent $30 \mathrm{~min}$ of BLB and assessments were taken before and after intervention.

Results of this study showed a significant increase in SBP, $\mathrm{PP}$, and MAP with a significant reduction in $\mathrm{HR}$ and no significant difference in DBP, RPP, and Do-P in the posttest 
assessment compared with baseline assessment [Table 1]. Subgroups (i.e., male group $[n=9]$ and female group $[n=11]$ ) analysis also showed a similar results (changes) in all the variables both in male and female groups as shown in the study group ( $n=20$ ) (9 males and 11 females together) except RPP. The RPP has significantly increased in male participants, while it has not change in female participants [Table 2]. None of the subjects reported any serious adverse effect either during or after the interventions.

\section{Discussion}

CVDs are the main cause of mortality and morbidity worldwide. Adequate changes in the lifestyle help to prevent the deaths from CVD. Parameters such as SBP, DBP, PP, and MAP are known as the best predictors of CVD risks. ${ }^{[12]}$ The objective of this study was to evaluate the BP, PR, and its' related variables following a 30 min session of BLB in healthy young adults.

\begin{tabular}{lcccc}
\hline \multicolumn{4}{l}{$\begin{array}{l}\text { Table 1: Baseline and posttest assessment of study group } \\
(\boldsymbol{n}=\mathbf{2 0})\end{array}$} \\
\hline Parameters & $\begin{array}{c}\text { Baseline } \\
(\boldsymbol{n}=\mathbf{2 0})\end{array}$ & $\begin{array}{c}\text { Posttest } \\
(\boldsymbol{n}=\mathbf{2 0})\end{array}$ & $\boldsymbol{T}$ or $\boldsymbol{Z}$ & $\boldsymbol{P}$ \\
& $105.80 \pm 8.20$ & $114.03 \pm 11.25$ & 7.598 & $<0.001^{* *}$ \\
\hline $\mathrm{SBP}(\mathrm{mmHg})^{\dagger}$ & $66.84 \pm 6.53$ & $69.22 \pm 5.19$ & 1.972 & 0.063 \\
$\mathrm{DBP}(\mathrm{mmHg})^{\dagger}$ & $74.93 \pm 6.55$ & $71.08 \pm 6.82$ & 4.132 & $0.001^{*}$ \\
$\mathrm{PR}(\text { beats } / \mathrm{min})^{\dagger}$ & $38.96 \pm 5.81$ & $44.81 \pm 9.45$ & 3.837 & $0.001^{*}$ \\
$\mathrm{PP}(\mathrm{mmHg})^{\dagger}$ & $79.83 \pm 6.59$ & $84.16 \pm 6.35$ & 3.416 & $0.001^{*}$ \\
$\mathrm{MAP}(\mathrm{mmHg})^{\star}$ & $79.19 \pm 8.38$ & $80.88 \pm 9.91$ & 1.435 & 0.168 \\
$\mathrm{RPP}^{\dagger}$ & $59.83 \pm 7.35$ & $59.77 \pm 6.85$ & 0.061 & 0.952 \\
$\mathrm{Do}^{\dagger} \mathrm{P}^{\dagger}$ &
\end{tabular}

$* P=0.001, * * P<0.001,{ }^{\dagger}$ Paired samples $t$-test, *Wilcoxon signed-rank test. All values are in mean \pm SD. BP: Blood pressure, SBP: Systolic BP, DBP: Diastolic BP, PR: Pulse rate, PP: Pulse pressure, MAP: Mean arterial pressure, RPP: Rate pressure product, Do-P: Double product, SD: Standard deviation
Results of this study showed a significant increase in SBP, PP, and MAP with an insignificant increase in DBP (slightly missed the level of significance $[P=0.063]$ ) and a significant reduction in $P R$ in the postintervention assessment compared with the preintervention assessment. It suggests that $30 \mathrm{~min}$ of BLB is effective in increasing SBP, PP, and MAP while reducing PR in young adults. SBP is the byproduct of cardiac output $(\mathrm{CO})$ and total peripheral resistance (TPR) (i.e., $\mathrm{SBP}=\mathrm{CO} \times \mathrm{TPR})$, wherein $\mathrm{CO}$ is the byproduct of $\mathrm{HR}$ and stroke volume (i.e. $\mathrm{CO}=\mathrm{HR} \times \mathrm{SV}$ ). Thus, HR forms one of the determinants of SBP. Hence, the reduction of $\mathrm{PR}$ (that represent the $\mathrm{HR}$ ) in this study should have reduced the SBP by decreasing CO ${ }^{[11]}$ However, the results of this study showed a significant increase in SBP. It suggests that the increase in SBP after BLB was not mediated through sympathetic activity because reduction in $\mathrm{HR} / \mathrm{PR}$ is an indicator of a state of altered or suppressed sympathetic activity. ${ }^{[13]}$

Sun exposure (i.e., sunbath including BLB) is known to produce hyperthermia ${ }^{[14]}$ that leads to increased secretion (hyperthermia induced) of cortisol. ${ }^{[15]}$ In a study, cortisol has shown to increase BP or induce hypertension by suppressing nitric oxide (a potent vasodilator) system and not through sympathetic dominance, because administration of cortisol produces either no change or suppression in sympathetic activity. Suppression of nitric oxide leads to reduction in vasodilatation and increase in TPR. ${ }^{[16]}$ Thus, the possible mechanism for the increased SBP in this study might attribute to hyperthermia-induced secretion of cortisol and/or increased TPR. Likewise, a significant increase in PP might attribute to a significant increase in SBP, while a significant increase in MAP might attribute to the significant increase in PP and increase in DBP. Since we did not measure either body temperature or cortisol levels in this study, studies are required in the future to warrant the proposed mechanism.

RPP and Do-P are the important indirect indicators of myocardial oxygen consumption and load on the heart. ${ }^{[1]}$

\begin{tabular}{|c|c|c|c|c|c|}
\hline Parameters & Gender & Baseline & Posttest & $T$ or $Z$ & $P$ \\
\hline \multirow[t]{2}{*}{$\overline{\mathrm{SBP}}(\mathrm{mmHg})^{\dagger}$} & Male & $110.44 \pm 9.21$ & $120.11 \pm 11.75$ & 7.990 & $<0.001 * * *$ \\
\hline & Female & $102.00 \pm 4.97$ & $109.05 \pm 8.34$ & 4.225 & $0.002 * *$ \\
\hline \multirow[t]{2}{*}{$\mathrm{DBP}(\mathrm{mmHg})^{\dagger}$} & Male & $67.51 \pm 7.90$ & $70.62 \pm 3.45$ & 1.426 & 0.192 \\
\hline & Female & $66.29 \pm 5.52$ & $68.07 \pm 6.19$ & 1.314 & 0.218 \\
\hline \multirow[t]{2}{*}{ PR (beats/min) ${ }^{\dagger}$} & Male & $72.72 \pm 7.86$ & $69.92 \pm 6.89$ & 2.740 & $0.025^{*}$ \\
\hline & Female & $76.74 \pm 4.91$ & $72.03 \pm 6.94$ & 3.212 & $0.009 * *$ \\
\hline \multirow[t]{2}{*}{$\mathrm{PP}(\mathrm{mmHg})^{\dagger}$} & Male & $42.93 \pm 5.50$ & $49.49 \pm 9.70$ & 2.604 & $0.031 *$ \\
\hline & Female & $35.71 \pm 3.76$ & $40.98 \pm 7.65$ & 2.702 & $0.022 *$ \\
\hline \multirow[t]{2}{*}{$\operatorname{MAP}(\mathrm{mmHg}) \dagger^{\star}$} & Male $^{\dagger}$ & $81.82 \pm 7.95$ & $87.12 \pm 5.75$ & 3.534 & $0.008 * *$ \\
\hline & Female $^{\ddagger}$ & $78.19 \pm 5.04$ & $81.73 \pm 5.98$ & 2.446 & $0.014 *$ \\
\hline \multirow[t]{2}{*}{ RPP (units) ${ }^{\dagger}$} & Male & $80.36 \pm 11.19$ & $83.98 \pm 11.78$ & 2.471 & $0.039^{*}$ \\
\hline & Female & $78.22 \pm 5.57$ & $78.34 \pm 7.73$ & 0.072 & 0.944 \\
\hline \multirow[t]{2}{*}{ Do-P (units) ${ }^{\dagger}$} & Male & $59.64 \pm 9.65$ & $60.88 \pm 6.93$ & 0.930 & 0.380 \\
\hline & Female & $59.99 \pm 5.31$ & $58.86 \pm 6.98$ & 0.739 & 0.477 \\
\hline
\end{tabular}

$* P<0.05, * * P<0.01, * * * P<0.001$, ${ }^{*}$ Paired samples $t$-test, ${ }^{*}$ Wilcoxon signed-rank test. All values are in mean \pm SD. BP: Blood pressure, SBP: Systolic BP, DBP: Diastolic BP, PR: Pulse rate, PP: Pulse pressure, MAP: Mean arterial pressure, RPP: Rate pressure product, Do-P: Double product, SD: Standard deviation 
Results of this study showed no significant difference in RPP and Do-P in the study group. However, the results of subgroups (male group and female group) analysis showed a significant increase in RPP in male subjects unlike female subjects. It suggests that $30 \mathrm{~min}$ of BLB may increase a workload on heart in male subjects and not in female subjects. The reason for increase in cardiac workload only in male is not clear.

BLB is commonly employed in many naturopathy hospital and clinics to treat skin diseases (e.g., psoriasis), obesity, and other metabolic disorders. ${ }^{[10]}$ In recent decades, increased prevalence of overweight and obesity among adolescents leading to increase in the prevalence of young adult hypertension. Young adulthood represents an important age interval for early hypertension prevention and treatment, which has the potential to reduce short-term and later life CVD risk. ${ }^{[2]}$ Since 30-min of BLB increase BP in young adults even though they are healthy, it might not be suitable in people who are at risk for developing hypertension in people who are at risk for developing hypertension or in patients with hypertension. Thus, BLB should be given with care in young adults. However, further studies are required to find the actual effect of BLB in patients with hypertension; because the physiological response of the hypertensive subjects might differ from that of healthy individuals as reported in a previous study on right nostril breathing (i.e., the cardiovascular effects of exclusive right nostril breathing in patients with hypertension are different than that of normal subjects). ${ }^{[17]}$

This is the first ever study reporting the effect of BLB on cardiovascular function in healthy individuals. Limitations of this study are as follows: small sample size and sample size were not calculated based on any previous study; lack of control group; assessed only the immediate effects and not either short-term or long-term effects; study was done on healthy individuals thus limiting its scope in applying it in pathological conditions. Inclusion of variables such as body temperature, cortisol level, baroreceptor sensitivity, autonomic function testing, and TPR might have provided better understanding of the effect of BLB. Hence, further studies (randomized controlled trials) are required with larger sample size and above-mentioned objective variables to find the precious effect of BLB with its underlying mechanism in general.

\section{Conclusion}

Results of this study suggest that 30 min of BLB might increases SBP, PP, and MAP and reduces PR with and without affecting cardiac workload in males and females, respectively.

\section{Financial support and sponsorship}

Nil.

\section{Conflicts of interest}

There are no conflicts of interest.

\section{RefEREnCES}

1. De Venecia T, Lu M, Figueredo VM. Hypertension in young adults. Postgrad Med 2016;128:201-7.

2. Zhang Y, Moran AE. Trends in the prevalence, awareness, treatment, and control of hypertension among young adults in the United States, 1999 to 2014. Hypertension 2017;70:736-42.

3. Alpert JS. The Jeremiah Metzger lecture: Jeremiah Metzger and the era of heliotherapy. Trans Am Clin Climatol Assoc 2015;126:219-26.

4. Mathew NS, Negi PS. Traditional uses, phytochemistry and pharmacology of wild banana (Musa acuminata Colla): A review. J Ethnopharmacol 2017;196:124-40.

5. Kumar S, Mishra CK, Ahuja A, Rani A, Nema RK. Phytoconstituents and Pharmacological activities of Musa paradisiaca Linn. Asian J Biochem Pharm Res 2012;4:199-206.

6. Kappel VD, Cazarolli LH, Pereira DF, Postal BG, Madoglio FA, Buss ZD, et al. Beneficial effects of banana leaves (Musaxparadisiaca) on glucose homeostasis: Multiple sites of action. Rev Bras Farmacogn 2013;23:706-15

7. Sahaa RK, Acharyaa S, Shovon SS, Royb P. Medicinal activities of the leaves of Musa sapientum var. sylvesteris in vitro. Asian Pac J Trop Biomed 2013;3:476-82.

8. Srinivas CR, Sundaram VS, Raju BA, Prabhu SK, Thirumurthy M, Bhaskar AC. Achieving asepsis of banana leaves for the management of toxic epidermal necrolysis. Indian J Dermatol Venereol Leprol 2006;72:201-2.

9. Sarma LK. Practical Nature Cure. $14^{\text {th }}$ ed. Puthukottai: The Nature-cure Publishing House; 2003. p. 253-60.

10. Neeraj NK. Miracles of Naturopathy and Yogic Sciences. $1^{\text {st }}$ ed. Jaipur: Popular Book Depot; 2009.

11. Mooventhan A. Immediate effect of ice bag application to head and spine on cardiovascular changes in healthy volunteers. Int $\mathrm{J}$ Health Allied Sci 2016;5:53-6.

12. Manjuladevi T, Mooventhan A, Manjunath NK. Immediate effect of hot chest pack on cardio-respiratory functions in healthy volunteers: A randomized cross-over study. Adv Integr Med 2018;5:63-8.

13. Mooventhan A, Nivethitha L. Effects of ice massage of the head and spine on heart rate variability in healthy volunteers. J Integr Med 2016;14:306-10

14. Holick MF. Biological effects of sunlight, ultraviolet radiation, visible light, infrared radiation and vitamin D for health. Anticancer Res 2016;36:1345-56.

15. Collins KJ, Few JD. Secretion and metabolism of cortisol and aldosterone during controlled hyperthermia. $\mathrm{J}$ Physiol 1979;292:1-14.

16. Kelly JJ, Mangos G, Williamson PM, Whitworth JA. Cortisol and hypertension. Clin Exp Pharmacol Physiol Suppl 1998;25:S51-6.

17. Bhavanani AB, Madanmohan, Sanjay Z. Suryanadi pranayama (right unilateral nostril breathing) May be safe for hypertensives. J Yoga Phys Ther $2012 ; 2: 118$. 